\title{
DIREITO DE FAMÍLIA: - PENSÃO ALIMENTÍCIA E TRIBUTAÇÃO
}

\author{
Jussara Suzi Assis Borges Nasser Ferreira \\ Maria de Fátima Ribeiro
}

SUMÁRIO: 1. Abordagem do Tema. 2. Imposto de Renda na Constituição Federal e no Código Tributário Nacional. 3. Alimentos: Natureza Juridica, Fundamentos e Hipótese de NãoIncidência. 4. Alimentos e a Miopia do Leão. 5. A Era das Reformas. 6. Conclusôes. 7. Bibliografia.

SUMMARY: 1. About the theme. 2. Tax of Rend in the Federal Constitution and in the National Tax Code. 3. Provisions: Legal Nature, Foundations and Hypothesis of Not-Incidence. 4. Provisions and the Myopia of the Lion. 5. The Time of Reforms. 6. Conclusion. 7. Bibliography.

SUMARIO: Acerca del Tema. 2. El Impuesto de Renda en la Constitución Federal y en el Código Tributario Nacional. 3. Los Alimentos: la Naturaleza Jurídica, los Fundamentos y la Hipótesis de Non-Incidencia. 4. Los Alimentos y la Miopía del León. 5. El Tiempo de Reformas. 6. Conclusión. 7. Bibliografia.

RESUMO: A desoneração tributária da pensão alimentícia representa o foco da análise critica do presente ensaio.A natureza jurídica e os fins a que se destinam os alimentos, desautorizam o enquadramento como se renda fosse. Não sendo renda, descabida a incidência do Imposto de Renda. Tributação que tal

\footnotetext{
"Doutora em Direito das Relaçóes Sociais pela Pontificia Lniversidade Gatolica de São Paulo. Protessora do Curso de Mestrado en Direito Negocial da Universidade Estadual de Londrina. Diretora da Faculdade de Direito da UNIMAR - Marila. Adrogada. Membro efetivo do Instituto dos Advogados Brasileiros - IAB. Vice-Presidente do CONPEDI.

* Doutora em Direito das Relaços Sociais pela Pontifich Universidade Citolica de São Paulo. Coordenadora do Curso de Mestrado en Direito Negocial da Universiddo Estadual de Londrina.
} 
é injusta, indevida e agride a moralidade da familia brasileira. Nessa perspectiva o estudo pretende apontar fundamentos sólidos acerca impropriedade da cobrança do Imposto de Renda sobre pensão alimentícia.

ABSTRACT: The disinvesting of a charge tax of the alimony represents the focus of the critical analysis of the gift ensaio.A legal nature and the ends the one that if the foods destine, disauthorize the framing as if income was. Not being income, been improper the incidence of the Income tax. Taxation that such is unjust, improper and attacks the morality of the Brazilian family. In this perspective the study about impropriety of the collection of the Income tax intends to point solid beddings on alimony.

RESUMEN: El exención de una carga impuesto de los alimentos representa el foco del análisis crítico de la naturaleza legal del regalo ensaio. A y de los extremos el que si los alimentos destinan, disauthorize enmarcar como si fuera la renta. No siendo renta, sido incorrecto la incidencia del impuesto sobre la renta. Impuestos que tales son injustos, incorrectos y ataques la moralidad de la familia brasileña. En esta perspectiva el estudio sobre la impropiedad de la colección del impuesto sobre la renta se prepone señalar lechos sólidos en alimentos.

PALAVRAS-CHAVES: Pensão alimentícia, Tributaçao indevida, Desoneração.

KEY-WORDS: Alimony. improper Taxation. Disinvesting of a charge.

PALABRAS LLAVES: Impuestos incorrectos de los alimentos. Exención de una carga. 


\section{1 - Abordagem do tema}

A desoneração tributária da pensão alimentícia representa o foco da análise crítica do presente ensaio.A natureza jurídica e os fins a que se destinam os alimentos, desautorizam o enquadramento como se fosse renda', proventos de qualquer natureza ou rendimentos. Assim sendo, descabida a incidência do Imposto de renda de Pessoa Física sobre alimentos. Tributação que tal é injusta, indevida e agride a moralidade da família brasileira.

Nessa perspectiva o estudo pretende apontar fundamentos sólidos acerca impropriedade da cobrança do Imposto de renda sobre pensão alimentícia.

\section{2 - Imposto de renda na constituição federal e no código tribu- tário nacional}

Nos termos expressos da Constituição Federal, a previsão do Sistema Tributário Nacional vem categorizada a partir do artigo 145. Referentemente aos impostos de competência da União, dispõe o artigo 153, inciso III:

Compete à União instituir impostos sobre:

$[\ldots]$

III - renda e proventos de qualquer natureza.

$[\ldots]$

O Código Tributário Nacional estabelece, no artigo 43:

Art. 43. O imposto, de competência da União, sobre a renda e proventos de qualquer natureza, tem como fato gerador a aquisição da disponibilidade econômica ou jurídica:

I - de renda, assim entendido o produto do capital, do trabalho ou da combinação de ambos;

II - de proventos de qualquer natureza, assim entendidos os acréscimos patrimoniais não compreendidos no inciso anterior.

O Decreto 3000, de 26 de março de 1999, que regulamenta a Tributação das Pessoas Físicas, em seu artigo $2^{\text {ä}}$ :

Art. 2a As pessoas físicas domiciliadas ou residentes no Brasil, titulares

\footnotetext{
1 - A Lei Complementar $n^{2} 104$ de 10.01.01, introduziu no Artigo 43 do CTN os parágrafos primeiro e segundo.
} 
de disponibilidade econômica ou jurídica de renda ou proventos de qualquer natureza, inclusive rendimentos e ganhos de capital, são contribuintes do imposto de renda, sem distinção da nacionalidade, sexo, idade, estado civil ou profissão (Lei n ${ }^{\mathrm{a}} 4.506$, de 30 de novembro de 1964, art. $1^{2}$, Lei $n^{\text {a }} 5.172$, de 25 de outubro de 1966, art. 43, e Lei n ${ }^{a} 8.383$, de 30 de dezembro de 1991, art. 4⿻3 ).

Cabe ressaltar, para fins desse estudo, a letra do artigo $5^{\text {a }}$, do mesmo Regulamento:

Art. $5^{\mathbf{a}}$ No caso de rendimentos percebidos em dinheiro a título de alimentos ou pensões em cumprimento de acordo homologado judicialmente ou decisão judicial, inclusive alimentos provisionais ou provisórios, verificando-se a incapacidade civil do alimentado, a tributação far-se-á em seu nome pelo tutor, curador ou responsável por sua guarda (Decreto-Lei $n^{a} 1.301$, de 1973, arts. $3^{3}, \S 1^{\underline{a}}$, e $^{\mathrm{a}}$ ).

Parágrafo único. Opcionalmente, o responsável pela manutenção do alimentado poderá considerá-lo seu dependente, incluindo os rendimentos deste em sua declaração (Lei $n^{2} 9.250$, de 26 de dezembro de 1995, art. 35, incisos III a V, e VII).

A doutrina que enfrenta a questão conceitual, acerca da renda, proventos de qualquer natureza e rendimentos apresenta os conceitos sob o ponto de vista jurídico, embora tenha também fortes entendimentos dos conceitos sob o ponto de vista econômico. ${ }^{2}$

Rubens Gomes de Sousa atribui ao legislador inteira liberdade para estabelecer o significado da palavra renda. No entanto, o conceito jurídico tributário de renda realmente há de ser buscado no Direito Positivo. Não se pode, todavia, admitir que o legislador ordinário desfrute de inteira liberdade para considerar renda tudo quanto pretenda tratar como tal para fins tributários. ${ }^{3}$

É que a Constituição Federal estabeleceu um sistema rígido de discriminação de competências tributárias, de forma que o Poder de Tributar deve ser exercido com observância dos preceitos constitucionais respectivos, e não de maneira inteiramente livre.

\footnotetext{
2 A doutrina, especialmente elaborada pelos economistas e financistas, posto que se trata de um conceito da Ciência Económica, tem apontado diversos significados para a palavra renda. As diversás teorias foram resumidas por FONROUGE e NAVARRINE em trếs grupos, a saber, (a) teorias da fonte e da rendaproduto; (b) teoria do incremento patrimonial e da renda-ingresso, ef funalmente, (c) a teoria do conceito legalista de renda.

Hugo de Brito Machado, A Supremacia Constitucional e o Imposto de renda, http// www.hugomachado.adv.br/artigos/SCIR.html
} 
Aliás, o simples fato de haver na Constituição vigente um dispositivo atribuindo à União competência para instituir e cobrar imposto sobre renda e proventos de qualquer natureza, é bastante para autorizar a conclusão de que o legislador não desfruta de inteira liberdade para definir o conteúdo dessa expressão. Renda $\mathrm{e}$ proventos de qualquer natureza é expressão que limita o âmbito de incidência de imposto federal. A não ser assim, ter-se-ia de ler a norma constitucional como se esta atribuísse competência à União para instituir e cobrar imposto sobre qualquer fato, a critério do legislador... E isto evidentemente não está escrito na norma constitucional. ${ }^{4}$

A doutrina também distingue, sob o ponto de vista econômico e fiscal, tais categorias:

a) Renda: é produto, fluxo ou acréscimo patrimonial, inconfundível do patrimônio de onde promana, assim entendido o capital, o trabalho ou a sua combinação;

b) Provento: é a forma específica de rendimento tributável, tecnicamente compreendida como o que é "fruto não da realização imediata e simultânea do seu patrimônio, mas sim, do acréscimo patrimonial resultante de uma atividade que já cessou, mas que ainda produz rendimentos",

c) Acréscimos Patrimoniais: sempre pressupõem a disponibilidade econômica ou jurídica, sendo certo que, mesmo não havendo a jurídica, a incorporação fisica e material ao patrimônio do contribuinte é sempre necessária. ${ }^{5}$

Finalmente, Roberto Quiroga Mosquera conceitua rendimentos como aqueles recebidos pelo trabalhador pelo exercício de uma função laboral, na qual houve consumo de energias pessoais para a consecução de um determinado objetivo ou tarefa. Assim, referidos rendimentos seriam o salário, o FGTS, o seguro desemprego, o décimo terceiro-salário,etc. ${ }^{6}$

Consoante determinação expressa no texto constitucional, o que do Código Tributário consta, e ainda, as especificações do Regulamento do Imposto de renda, percebe-se a impropriedade da tributação sobre

\footnotetext{
${ }^{4}$ Ibidcm. É induvidoso que, em qualquer caso, se as palavras empregadas nas normas da constituição puderem ser livremente definidas pelo legislador ordinário, a supremacia da constituição não será mais que simples ornamento da literatura jurídica. Através de definições legais todos os dispositivos da lei maior poderão ser alterados pelo legislador ordinário.

s LEITE, Geílson Salomão. CONSIDERACÕES JURÍDICAS EM TORNO DO CONCEITO CONSTITUCIONAL DE RENDA E A AJUDA DE CUSTO PARLAMENTAR. In http:// www.direitopublico.com.br/, capturado em 20 de setembro de 2003.

"Apud LEITE, Geílson Salomão, Renda e proventos de qualquer natureza. O imposto e o conceito constitucional. Dialética. São Paulo, p. 56.
} 
alimentos. A previsão do artigo $2^{\text {a }}$, do RIR, determina categoricamente que os obrigados a prestarem o imposto de renda são as pessoas físicas titulares de disponibilidades econômicas ou jurídicas, de renda ou proventos de qualquer natureza, inclusive rendimento e ganhos de capital. Vê-se claramente que o alimentando não se inclui em quaisquer das hipóteses de incidência tributária, despossuído que é, impossível reconhecer-lhe atributos como os referidos pelo Regulamento.

A legislação que direta ou indiretamente define o alcance da expressão renda e proventos de qualquer natureza, está sujeita ao controle de constitucionalidade.

Além disto, é importante observar que o Código Tributário Nacional definiu renda como o produto do capital, do trabalho ou da combinaçăo de ambos, e proventos de qualquer natureza como os acréscimos patrimoniais não compreendidos no conceito de renda. (art. 43, itens I e II). Adotou, portanto, o conceito de renda acréscimo. Sem acréscimo patrimonial não há, segundo o Código, nem renda, nem proventos.

Como se vê, o Código Tributário Nacional estreitou o âmbito de liberdade do legislador ordinário, que não poderá definir como renda, ou como proventos, algo que não seja na verdade um acréscimo patrimonial.

Balizado pela melhor doutrina, os rendimentos referidos tanto no artigo $2^{a}$, Regulamento, estão delimitados como aqueles recebidos em decorrência de fruto do trabalho, pelo exercício de função laboral. $\mathrm{O}$ artigo $5^{\mathrm{a}}$, à falta de melhor enquadramento, força o reconhecimento de alimentos, a ele se referindo como "caso de rendimentos percebidos em dinheiro".

A previsão legal afronta o texto constitucional, exatamente quando tenta expressar aquilo que, como decorrência das limitações jurídicas impostas pela Constituição, em sede de matéria tributária, não houve por bem respeitar. A menção anterior aos artigos 153, III, da Constituição Federal, 43, I e II, do Código Tributário Nacional, definem, de forma categórica as possibilidades de incidência tributária.

De outra parte, o artigo 43, do RIR, determina que "são tributáveis os rendimentos do trabalho assalariado". Ainda merece referência o plano conceitual, onde se descrevem os acréscimos patrimoniais. Como foi demonstrado neste ambiente também não se inserem os alimentos, que por sua natureza jurídica, fundamentos, e fins a que se destinam, não 
comportam a incidência do Imposto de renda.

O significado da expressão acréscimo patrimonial, não refere conceito de sentido vago, ou ambíguo. Pode-se dizer realmente que tal expressão é vaga, ou que é ambigua. Afirmar que as palavras e expressões jurídicas são, em regra, ambiguas e imprecisas não quer dizer porém que não tenham elas significado determinável. Por isto mesmo, a afirmação da vaguidade, ou ambiguidade, de uma palavra, ou expressão, utilizada em uma norma jurídica, não se presta como fundamento para justificar a inteira liberdade de seu intérprete, ou aplicador.

Pode-se afirmar que, no sistema jurídico brasileiro, a expressão renda e proventos de qualquer natureza só abrange os fatos que possam ser considerados como acréscimo patrimonial; e o legislador ordinário não pode definir como acréscimo patrimonial aquilo que evidentemente não o seja, na linguagem comum, cabendo ao Poder Judiciário, e em última instância ao SUPREMO TRIBUNAL FEDERAL, dizer o que se há de entender como acréscimo patrimonial, declarando a inconstitucionalidade do dispositivo de lei que estabelecer conceito diverso.

Repita-se: alimentos não são renda; não são proventos de qualquer natureza; não são rendimentos; e não caracterizam acréscimos patrimoniais.

\section{3 - Alimentos: natureza jurídica - fundamentos - e hipótese de não-incidência}

Pela regra geral estabelecida pela Constituição Federal, no artigo 226, caput, a familia é reconhecida como "base da sociedade, e tem especial proteção do Estado". Assim, a família contemporânea, diferentemente, da família moderna do século passado, vem concebida a partir de um desenho marcado pela constitucionalização, que prestigia a proteção da família, com destaque para a dignidade da pessoa humana, a igualdade familiar, $\mathrm{e}$ a prevalência da tutela dos interesses da criança e do adolescente.

Houve um avanço significativo na cena familiar, considerando que a finalidade do direito de família contemporâneo consiste, sobretudo, em conseguir um melhor equilibrio das relações familiares.

É nesse cenário que a questão da tributação dos alimentos representa desequilíbrio, na contramão das conquistas das muitas igualdades, finalmente reconhecidas, no ambiente da família brasileira. 
Os alimentos são tradicionalmente conceituados pela uniformidade da doutrina e jurisprudência, como prestação para a satisfação das necessidades do alimentando que por si não tem meios possíveis para provê-las. As necessidades referidas são de regra, aquelas indispensáveis à vida de uma pessoa. Então, os alimentos constituem-se em dever da família ${ }^{7}$.

$\mathrm{Na}$ sua função e finalidade, os alimentos visam fornecer ao necessitado, aquilo que é preciso para a sua manutenção entendida esta em sentido amplo, de modo a assegurar-lhe os meios de subsistência, se o mesmo não tem de onde tirá-los, ou se encontra impossibilitado de produzi-los ${ }^{8}$.

A finalidade dos alimentos é assegurar o DIREITO A VIDA, substituindo a assistência da família à solidariedade social, que une os membros da coletividade, pois as pessoas necessitadas, que não tenham parentes, ficam, em tese, sustentadas pelo Estado. O primeiro ćrculo de solidariedade é o da familia, e somente na sua falta é que o necessitado deve recorrer ao Estado?.

Os alimentos deverão ser entendidos, ainda, como prestações para a satisfação das necessidades de quem não pode provê-las por $\mathbf{s i}^{10}$.

O Código Civil de 2002 trata da questão referente à necessidade dos alimentos, em contraponto com a possibilidade daquele que deverá prestálos. É o que dispõe o artigo 1694 e seus parágrafos.

Já o 1695 estabelece que: "a necessidade consiste em não ter bens, nem poder prover, pelo seu trabalho, à própria mantença." A possibilidade é definida como poder fornecer a verba, sem desfalque do necessário ao seu sustento.

Em verdade, tais disposições já se encontravam consagradas nos artigos 399 e 400, do Código Civil de 1916.

A satisfação da obrigação alimentar é matéria abordada no artigo 1701, do Código de 2002. A única inovação é aquela que diz respeito que "hospedando ou pensionando o alimentando, fica o alimentante obrigado, ainda, a prestar o necessário à sua educação quando menor."

As demais formas previstas foram apenas reproduzidas do artigo 403, do Código de 1916.

Nesse passo deve ser considerado o caráter patrimonial ou näo, da obrigação alimentícia.

GOMES, Orlando. Direito de Família, p. 428

"CAHALI, Yussef Sahid. Dos alimentos. Săo Paulo, RT, 1999, p. 16.

"WALD, Arnoldo. O novo Direito de Familia. São Paulo, Saraiva, 2002, p. 42.

10 FACHIN, Luiz Edson. Elementos criticos do Direito de Família, p. 268, apud COSTA, Mara Aracy Menezes da, in Pensâa alimenticia entre cônjuges e o conceito da necessidade - Familia e Cidadania, o Novo CCB e a Vacatio Legis. Anais do III Congresso Brasileiro de Direito de Familia, p. 199. 
Da doutrina estrangeira, traz-se à colação a lição de Antonio $\mathrm{Cicu}^{\mathrm{It}}$, que compreende a prestação alimentar na disciplina das relações familiares, e não obrigacionais. Os alimentos, nesse perspectiva, correspondem a um interesse familiar, contendo em si uma obrigação de cuidado com a pessoa, e se distinguindo assim, de qualquer outra obrigação alimentar ex lege, seja pelo caráter não patrimonial, seja pela sua finalidade familiar superior; a peculiaridade que the é característica, a estrita personalidade, a imprescritibilidade, a irrenunciabilidade, a impenhorabilidade the atribuiriam um caráter familiar tal, que o torno único nas relações interprivadas.

Daí recusar caráter patrimonial ao direito que pertence ao alimentando: o elemento ativo do patrimônio deste, não seria o direito aos alimentos, visto que não integra o seu patrimônio como um bem de que possa dispor, um valor que aumentasse e que servisse de garantia aos credores do mesmo; não havendo também, um interesse patrimonial do alimentando, um interesse individual com tutela da lei, mas apenas um interesse de ordem superior e meramente familiar; e, inversamente, o debito por alimentos não constituiria no patrimônio do alimentante como verba a ser inserida em seu passivo, eis que não é levado em linha de conta, quando se tem que avaliar o patrimônio do prestante, na sua consistência econômica; não existiria nem um interesse, nem um encargo de natureza patrimonial, eis que prevalecendo, sobretudo, estaria o caráter SUPERIOR, SOCIAL E FAMILIAR do instituto ${ }^{12}$.

Reconhecido o caráter não patrimonial da pensão alimentícia, no âmbito das relações familiares, outro ponto deve ser observado, pois que de relevo.

A obrigação alimentar de natureza familiar não se modifica ou altera, a não ser pela forma, por força das mudanças que possam ocorrer na estruturação da família, via de regra, geradas pela separação ou divórcio. Se desfeito o casamento entre os cônjuges, a condição familiar, e a respectiva obrigação de prestar alimentos aos que deles necessitam, permanecem inalterados. Em tais circunstâncias, altera-se, tão somente, a forma de prestação da pensão alimentícia. Também por esses fundamentos não se autoriza o tratamento que a Receita Federal vem dando a matéria.

"CICU, Antonio. La natureza giuridica dellobbligazione tra coniugi In Scriti Minori, Milano, Giufrè, 1965.

i. Cf. CICU, idem, ibidem. 
O imposto de renda, a rigor, deve ser cobrado somente de quem ganha mais que o suficiente para as despesas para seus gastos e de seus dependentes. Renda, na definição do art. 43 do Código Tributário Nacional, é acréscimo patrimonial. À luz dessa definição, só deve ser considerado renda o ganho que permite, ao menos em tese, algum acréscimo patrimonial.. Não é razoável entender-se como renda o ganho que não é suficiente sequer para o custeio das despesas, absolutamente necessárias, à sobrevivência do contribuinte e de seus dependentes estando sob o mesmo teto ou não.

Considerando a doutrina que não reconhece a natureza patrimonial dos alimentos, mais os fundamentos acerca da simples alteração formal da prestação alimenticia, e ainda, o conceito econômico fiscal de acréscimos patrimoniais, impossível admitir-se a incidência do imposto de renda, repita-se à exaustão, sobre verba alimentar de natureza familiar.

\section{4 - Alimentos e a miopia do leão}

Atendendo à previsão legal, que se mantém praticamente idêntica a do Código de 1916, de há muito os alimentos estipulados amigavelmente ou fixados por determinação judicial limitam-se ao estreito provimento das necessidades do alimentando. Qualquer desconto da pensão alimentícia implica na redução dos valores que deveriam atender o alimentando. Descontado o imposto de renda da pensão alimentícia recebida, há inegável, diminuição do quantum da pensão, jamais calculado incluindo algum valor para atender essa destinação em específico. Como não há tal previsão, o que ocorre é a real diminuição do quantum que se já é justo para atender fins delimitados, torna-se mais exíguo, e no mais das vezes colaborando para o arroxo financeiro do alimentando. ${ }^{13}$

A cobrança do imposto de renda sobre pensão alimentícia não enfrenta questionamentos e reflexões por parte da doutrina e muito menos pela jurisprudência.

Quando toda a estrutura familiar, hoje plural, é repensando, indispensável se faz indagar essa modalidade de tributação.

\footnotetext{
Sempre que a tributação impedir on dificultar a realização do essencial ou do útil em relação a toda a sociedade on parte dęla e até mesmo a determinada pessoa, será desmedida e, poderá ter caráter confiscatorio, por nẵo ser aproptiação legitima de bens desses integrantes do corpo social. José Carlos Graça Wagner - Trbutaço Social do Trabaho e do Capital. Resenha Tributária, SI, 1982, p. 21.
} 
É certo que a família não pode ser compreendida como ente econômico, sua organização tem outra conformação para a sociedade e para o Estado. Entretanto, em alguns momentos, especialmente nos de crise familiar o Estado compreende a família a partir de sua expressão econômica, e assim passa a tributar a partilha de bens, venda do patrimônio, situações conhecidas e reconhecidas pelo Direito como de tributação.

Há necessidade urgente de incorporar ao Direito Tributário, o Direito Constitucional de Família. Tanto a jurisprudência como a doutrina alemã consideraram princípio tributário fundamental, a proteção à família. $\mathrm{O}$ Tribunal Constitucional tedesco declarou inconstitucional o sistema anterior de avaliação conjunta dos cônjuges, face ao artigo $6^{\underline{a}}$, I, da Lei Fundamental que coloca o casamento e a família sob a proteção especial do ordenamento estatal. Assim, evita-se a incidência de alíquotas progressivas mais elevadas e se assegura uma conseqüente diminuição da progressão.

Mizabel Derzi, ressalta que o casamento e a família não podem ser tomados como motivo para agravar o dever do imposto. Seria inadimissível o tratamento desigual frente aos não casados. ${ }^{14}$

Além disso, Hans Spanner, lembrando o mesmo artigo $6^{\underline{a}}$ da Constituição alemã, pondera a necessidade de se proteger a manutenção econômica da família. Em resumo, para tal doutrina, se a lei tributária, por seus gravames, beneficiar o concubinato em detrimento do casamento, ou desconsiderar os encargos familiares, privilegiando os solteiros sem filhos, haverá inconstitucionalidade. ${ }^{15}$

No Brasil, não podem ser outros, os princípios norteadores do Direito Tributário. A Constituição Federal assegura especial proteção do Estado à família. E, embora reconheça a união estável como entidade familiar, determina que a lei facilite sua conversão em casamento (ART. 226, §3)

Pode ser observado que o dever de assistir, educar e criar os filhos menores, consagrados no art. 229 não pode desencadear conseqüências fiscais mais gravosas ao devedor da pensão alimentícia. O planejamento familiar é de livre decisão do casal, não podendo haver forma coercitiva por parte de instituições oficiais ou privadas.

Familia e Tributação. In Revista da Faculdade de Direito da UFMG, n. 32 , p. 156.

1.5 - Ibidem, p. 157. 
Assim, a legislação do imposto de renda não pode limitar o número de deduçōes por dependente, nem ainda ignorar os demais gastos necessários à criação, à educação e plena assistência devida aos filhos.

Ao cumprimento de um dever (o de sustentar, educar e assistir os filhos menores) previsto na Carta Constitucional, o ordenamento tem que assegurar coerente e lógica eficácia. ${ }^{16}$

As Constituições anteriores não previam as regras de progressividade, pessoalidade, capacidade contributiva, generalidade do imposto de renda, da vedação de se utilizar tributo com efeito de confisco, do planejamento familiar como estrita decisão do casal e do dever de sustentar e educar os filhos menores, tudo isto está previsto na atual Carta Política. No entanto, a legislação ordinária sobre o imposto de renda deixa a desejar, quando as legislaçôes anteriores permitiam a dedução de gastos com dependentes, educação, saúde e moradia, embora com limites. A partir da vigência da Constituição Federal de 1988, as alíquotas progressivas do imposto de renda foram reduzidas substancialmente, desconsiderando encargos pessoais e familiares, de modo geral.

Alimento não é renda e com esta não se confunde, não devendo merecer o tratamento como se rendimento fosse, e nem tampouco proventos de qualquer natureza.

Nesta mesma linha de raciocínio, é interessante trazer a posição de Hugo de Brito Machado ${ }^{17}$, quando ensina que:

uma das bases mais universais da tributação no mundo atual é a renda que, por definição, é crescimento patrimonial resultante do capital, do trabalho, ou da combinação desses dois fatores. Verifica-se, porém, que apenas a renda derivada do trabalho, que muitas vezes não chega a ser propriamente renda porque não implica aumento patrimonial porque é inteiramente consumida no atendimento das necessidades imediatas do trabalhador, tem sido alvo da tributação no Brasil.

Por isto mesmo, aliás, é que somos o país onde existe uma das mais elevadas concentrações de riqueza e a mais injusta distribuição da renda, questiona o autor em referência, ressaltando que o governo poderia minimizar parte da injustiça social, tributando de forma mais expressiva os ganhos provenientes do capital. Enquanto isto eleva-se brutalmente os encargos

Tributaçäo Capital e Trabaho, http:/wwwhugomachado.advbr/artigos/tethtml en 16.10 .03 Conferir Comentiros ao Cólgo Tributáno Nacional voll, Atias, SP, 2003, do mesmo autor. 
tributários sobre o trabalho. Aumenta-se a contribuição social dos servidores públicos, e cria-se contribuição sobre os proventos dos aposentados. Vinte e cinco por cento. Além do imposto de renda que é de vinte e sete e meio por cento. Porque não tributar o capital, questiona o citado jurista? Ou será que o trabalhador brasileiro vai submeter-se ao sacrifício de suportar sozinho, indefinidamente, a pesada carga tributária?

Preocupa-se o governo apenas com a possibilidade de fuga de capitais para outros países e diminuição de investimentos.

Da mesma forma podem ser considerados as despesas com a educação. A dedução dos gastos com a educação é muito pequena, que não corresponde aos valores realmente desprendidos. Para a Receita Federal o imposto deve ser neutro, isto é, deve ser um instrumento de arrecadação, simplesmente. Não deve ser utilizado como instrumento de redistribuição da riqueza, pelo que percebe.

Modernamente, porém, o imposto é visto pelos mais ilustres mestres da Ciência das Finanças e da Política Fiscal como um instrumento de intervenção do Estado na economia, e especialmente como um instrumento de redistribuição de riqueza. Essa postura em muitos casos afronta a Constituição, e no que concerne especificamente ao Imposto de renda, viola norma expressa da Lei Maior. Com efeito, o art. 153, $\S 2^{\circ}$, inciso I, da vigente Constituição Federal, assevera que o imposto de renda será informado pelos critérios da generalidade, da universalidade e da progressividade, na forma da lei.

Por outro lado, no que concerne à questão das deduções de gastos com a educação, estará tributando despesas e não renda. Segundo, o de que a Constituição assegura o direito à educação, que é dever do Estado e será promovida $e$ incentivada com a colaboração da sociedade. A conta da educação, porém, há de ser compartilhada com toda a sociedade, e a melhor forma de fazê-lo, além. da oferta de escola pública gratuita que a final é paga pelos contribuintes em geral, é, sem dúvida, admitir-se a dedução integral, sem limites, dos gastos com a educação. Gastos efetivos, é certo, mas a questão de possiveis fraudes é outro problema que reclama solução diversa, não sendo justo que a pretexto de evitarse a fraude se anule o direito constitucionalmente assegurado.

Assim, pelo menos para os que na interpretação da Constituição prestigiam o princípio da máxima efetividade de suas normas, é clara a inconstitucionalidade do dispositivo da legislação tributária que impóe limite para dedução dos gastos com educação. ${ }^{18}$

\footnotetext{
2. . Confira - Hugo de Brito Machado, Gastos com Educação e Imposto de renda htep// www hugomachado.adv.br/artigos/err.btrl
} 
Com isto é possivel fazer um paralelo entre a tributação dos ganhos provenientes do resultado do trabalho e do capital, dedução dos gastos com educação e os valores provenientes do recebimento da pensão alimentícia.

Assim sendo, aufere renda ou rendimento aquele que paga a pensão e não aquele que recebe a pensão. Numa lógica do avesso o fisco contemplando o pagador da pensão com o desconto integral no Imposto de renda dos valores pagos com a pensão alimentícia, privilegiando assim o mais forte, tornando menos oneroso o ato de pagar pensão. $\mathrm{Na}$ seqüencia, o fisco, em verdade se reembolsa da dedução integral que concede ao pagador, cobrando o Imposto de renda do alimentando, retirando daquele valor, previamente calculado, parcela destinada para atender necessidades vitais. $O$ menos protegido e assim reconhecido, aliás por tais condições é que recebe alimentos, vê-se agora como o lado mais fraco, obrigado a pagar o Imposto de renda, caracterizando uma situação perversa, principalmente levando-se em conta que o grande número de alimentandos no país, são de menores e adolescentes; aqueles mesmos que o Estado deve assegurar absoluta prioridade, o direito à vida, à saúde, à alimentação, à educação, à profissionalização, à cultura, à dignidade, ao respeito, colocando a salvo de toda negligência, exploração, violência, crueldade e opressäo.

A incidência do Imposto de renda sobre os valores auferidos como pensão alimentícia é uma forma de exploração desnecessária do menor e do adolescente, uma violência financeira e seguramente ato de opressão fiscal.

\section{5 - A era das reformas}

A reforma tributária que tramita pelo Congresso Nacional, destaca grandes debates travados. Nem por uma vez, visualizou-se, por parte dos reformadores, uma única preocupação em relação à família. As atenções voltam-se todas para o cenário dos grandes contribuintes e dos grandes arrecadadores, com a própria União, Estados e Municípios.

Se por um lado o Estado buscou tutelar o Direito de Família contemporâneo, expressando progressos apreciáveis, de outro manteve as estruturas rígidas do século passado não admitindo tratamento adequado para o posicionamento familiar. Não é preciso reforma 
tributária para rever a matéria em foco, basta reformar a legislação do Imposto de renda, que poderá isentar de tributação os alimentos de qualquer natureza - e assim o alimentando receberia tratamento mais digno e cidadão, como fez a Carta Constitucional ao dispor sobre a tributação da renda dos contribuintes maiores de 65 anos. Desta forma, estar-se-ia diante dos ditames de justiça social apregoados pela referida Carta. Se é dever da família, da sociedade e do Estado assegurar à criança e ao adolescente, com absoluta prioridade o direito à vida, à saúde, à alimentação e demais condiçôes de vivência e convivência, imbuídos nestes ditames, assegurados pelo artigo 226 da Constituição, deve ser verificado que a legislaçäo infraconstitucional do imposto de renda, ao tributar os alimentos, não se coaduna com os ditames constitucionais aí estatuídos.

A supremacia constitucional, consiste em sustentar a necessidade de leis para regulamentar dispositivos da Constituição, e na afirmação da natureza meramente programática de muitas de suas normas.

Inúmeros exemplos podem ser citados, nos quais se nega a supremacia constitucional, seja pela simples desconsideração da norma da Constituição, seja pelo argumento de que tal norma está a depender de regulamentação, ou ainda de que tal norma é meramente programática. Em muitos casos resta evidente que, na prática, valem muito mais as leis, e até as normas infralegais, do que a constituição. A supremacia desta, portanto, tem sido simplesmente retórica.

É importante, porém, que se modifique essa mentalidade, porque a supremacia constitucional é o mais adequado caminho para a realização do princípio da isonomia, o mais fundamental de todos os princípios jurídicos, e para a preservação da própria unidade do sistema jurídico.

Ainda quando a norma da Constituição seja somente programática, tem-se de considerá-la como elemento valioso na interpretação. Os valores incorporados nas normas da constituição devem servir como balizas para o intérprete de toda e qualquer norma do sistema jurídico. Mesmo quando genérica ou programática, a norma constitucional possui, em algum grau, eficácia e operatividade.

A supremacia constitucional é a única garantia que o Direito pode oferecer contra o arbítrio do Estado, especialmente quando este se expressa através de lei. Com inteira propriedade assevera o Ministro Celso de Mello, do Supremo Tribunal Federal: O poder absoluto exercido pelo Estado, sem quaisquer restriçóes e controles, inviabiliza, numa comunidade estatal 
concreta, a prática efetiva das liberdades e o exercício dos direitos e garantias individuais ou coletivos. É preciso respeitar, de modo incondicional, os parâmetros de atuação delineados no texto constitucional. Uma Constituição escrita não confrgura mera peça jurídica, nem é simples estrutura de normatividade e nem pode caracterizar um irrelevante acidente histórico na vida dos Povos e das Nações. ${ }^{19}$

Daí porque a lei ordinária referente ao imposto de renda deverá contemplar os ditames constitucionais de proteção à família, base da sociedade brasileira, fazendo valer assim, as expressões constitucionais, como definidas pela Magna Carta. Permanecendo inalterada a matéria, e considerando a afronta à supremacia constitucional, como demonstrada, faz-se imprescindível reconhecer a inconstitucionalidade da cobrança do imposto de renda sobre pensão alimentícia, no âmbito das relações familiares

\section{6- Conclusões}

- Em termos fiscais é preciso que se tenha uma melhor proteção da família, com a definição e reconhecimento do regime alimentário suas possibilidades e efetivação.

- A legislação do imposto de renda deve ser reformada para isentar de tributação os alimentos devidos em razão de laços familiares, dedicando ao alimentando tratamento mais digno e cidadão.

- Os alimentos são definidos pela unanimidade da doutrina, como prestação para a satisfação das necessidades do alimentando que por si não tem meios possíveis para provê-los.

- Os alimentos não se confundem com os conceitos de renda, proventos de qualquer natureza, rendimentos, não se caracterizando como acréscimos patrimoniais.

- O reconhecimento da inconstitucionalidade da cobrança do imposto de renda sobre pensão alimentícia, no âmbito das relações familiares se impõe, em nome da supremacia constitucional, enquanto única garantia que o Direito pode oferecer contra o arbítrio do Estado. 


\section{BIBLIOGRAFIA}

CAHALI, Yussef Sahid. Dos alimentos. São Paulo, RT, 1999, p. 16. CARVAlHO, Paulo de Barros. Curso de Barros Carvalho. São Paulo, Saraiva, 2003.

CICU, Antonio. La natureza giuridica dell'obbligazione tra coniugi. In Scritti Minori, Milano, Giuffrè, 1965.

COELHO, Sacha Calmon Navarro. Curso de Direito Tributário Brasileiro. RJ, Forense, 1999.

DERZI, Misabel de Abreu Machado. Os conceitos de Renda e Patrimônio, Belo Horizonte, Del Rey, 1992.

DERZI, Misabel de Abreu. Família e Tributação. A vedação de utilizar o tributo com efeito de Confisco. In Revista da Faculdade de Direito da Universidade Federal de Minas Gerais, p.145/164, n.32. Belo Horizonte. FACHIN, Luiz Edson. Elementos críticos do Direito de Família, p. 268, apud COSTA, Maria Aracy Menezes da, in Pensão alimentícia entre cônjuges e o conceito da necessidade - Família e Cidadania, o Novo CCB e a Vacatio Legis. Anais do III Congresso Brasileiro de Direito de Família, p. 199.

GOMES, Orlando. Direito de Família, pág. 428.

LEITE, Geílson Salomão. Considerações jurídicas em torno do conceito constitucional de renda e a ajuda de custo parlamentar. In http:// www.direitopublico.com.br/, capturado em 20 de setembro de 2003.

MACHADO, Hugo de Brito. A Supremacia Constitucional e o Imposto de renda in in http://www.hugomachado.adv.br/artigos/artigos.html MACHADO, Hugo de Brito. Comentários ao Código Tributário Nacional. Vol. I, Atlas, SP, 2003.

MACHADO, Hugo de Brito. Curso de Direito Tributário. São Paulo, Malheiros, 2003.

MARTINS, Ives Gandra da Silva (coord.) Direitos Fundamentais do Contribuinte. São Paulo, Revista dos Tribunais, 2000.

RODRIGUES, Silvio. Direito Civil:vol. 06 - 27. Ed. - São Paulo: Saraiva, 2002. SILVA, Fernando A. Rezende da. O imposto sobre a Renda e a Justiça Fiscal. IPEA, SP, 1974.

WAGNER, José Carlos Graça. Tributação Social do Trabalho e do Capital. São Paulo, Resenha Tributária, 1982.

WALD, Arnoldo. O novo Direito de Família. São Paulo, Saraiva, 2002, p. 42. 